\title{
Salt Preference According to a Questionnaire vs. Dietary Salt Intake Estimated by a Spot Urine Method in Participants at a Health Check-up Center
}

\author{
Tomoko Hashimoto, Fukuko Yagami, Masahiko Owada, \\ Takashi Sugawara and Minoru Kawamura
}

\begin{abstract}
Objective Salt intake restriction is important to health maintenance in subjects tending toward excessive intake. For convenience salt intake is ordinarily estimated at health check up centers using a salt-preference questionnaire, but whether or not the questionnaire identifies excessive salt consumers is unclear.

Methods Daily salt intake in 725 subjects including 452 men examined at our health-check center was estimated by a spot urine method developed by Kawasaki et al (Clin Exp Pharmacol Physiol 20:7-14, 1993). Results from the questionnaire were used to divide into salt preference and non-salt preference groups.

Results Daily salt intake estimated by the spot urine method was $13.5 \pm 3.5 \mathrm{~g}$ in male subjects and $12.4 \pm 3.1$ $\mathrm{g}$ in female subjects. Salt preference subjects included $42 \%$ men and $24 \%$ of women. As a daily salt intake of less than $10 \mathrm{~g}$ is recommended for the general population in Japan, subjects whose salt intake exceeded 10 $\mathrm{g}$ were considered excessive salt consumers. Among men, excessive salt consumers comprised $85 \%$ of the salt preference group and $84 \%$ of the non-salt preference group. Among women, $88 \%$ of the salt preference group and $76 \%$ of the non-salt preference group were excessive consumers.

Conclusions A simple questionnaire for salt preference was not effective in identifying excessive salt consumers. Convenient, reliable methods for the estimation of salt intake, such as the spot urine method, are recommended in place of the questionaire.
\end{abstract}

Key words: gender-associated difference, health-checkup, salt preference, salt intake, spot urine, Japanese population

(Inter Med 47: 399-403, 2008)

(DOI: 10.2169/internalmedicine.47.0622)

\section{Introduction}

Chronically high salt intake is important in the onset and maintenance of hypertension $(1,2)$, and also it is a risk factor independent of blood pressure not only for cardiovascular disease $(1,2)$, but also for gastric cancer $(3,4)$. Restriction of salt intake is important in maintaining health in subjects with an excessive intake. Japanese are known to have higher salt intake than many other populations $(5,6)$. Although a daily salt intake below $10 \mathrm{~g}$ is recommended for the general population in Japan, the average salt intake according to a national nutrition survey in 2004 was $11 \mathrm{~g}$ per day (7), suggesting that a considerable number of persons need to limit salt intake. Accordingly, estimation of salt intake in health check-up participants is important for accurate advice concerning the need to reduce salt intake. Daily salt intake may be estimated using food consumption data obtained from interviews and diaries (8), or from 24 hour urinary sodium excretion (9). Procedures for both methods are relatively inconvenient. Even hypertensive patients at an outpatient clinic do not typically undergo evaluation of salt intake by any method because of the inconvenience of determination (10). At a health check-up center, where the estimation of salt intake must be accomplished for many subjects, intake is usually estimated by a questionnaire concern- 
ing salt preference, for reasons of convenience. However, whether the questionnaire method is a reliable indicator of salt intake is not known.

Kawasaki et al (11) developed a convenient method for evaluating daily salt intake that is applicable for healthcheckup participants. Daily salt intake can be obtained by calculations involving multiplication of predicted creatinine excretion by the ratio of sodium and creatinine obtained from a "spot" urine specimen. Values obtained by the spot urine method correlated highly with those from determinations of 24 hour urinary sodium excretion $(r=0.73)(11)$. Usefulness of the spot urine method has been confirmed in population studies $(12,13)$ and in hypertensive patients treated with medication (14).

We presently investigated whether or not a questionnaire concerning salt preference reliably indicated salt intake as simultaneously estimated by the spot urine method.

\section{Study Subjects}

We studied 454 male and 274 female participants undergoing a health check-up at the Iwate Prefectural Central Hospital, Japan. Male participants underwent check-ups from April 2001 to March 2002, and female participants from April 2001 to March 2003. During the study interval, 3 women underwent the check-up twice; their second data set was deleted, so 271 data sets from women were subjected to further analysis. Written informed consent for this study was obtained from all subjects. Approval for the study also was obtained from the Ethics Committee of the Iwate Prefectural Central Hospital.

\section{Methods}

Subjects were advised to enter the health check-up center after the first voiding upon awakening, without taking breakfast. Urine was collected upon arrival at 9:00. Using the spot urine specimen, we calculated daily excretion of sodium by the Kawasaki formula (11), which is based on the subject's gender, age, body weight, and height, as well as sodium and creatinine concentrations in the urine sample. Because approximately $90 \%$ of sodium intake is excreted in the urine (15), daily excretion of sodium was considered roughly equal to daily sodium intake; this was expressed as grams of sodium chloride per day as suggested by the Japanese Guidelines (16).

The formula for salt intake (grams of sodium chloride per day) was $0.96 \times \sqrt{(\mathrm{UNa} / \mathrm{UCr} / 10) \times(15.1 \times \mathrm{BW}+7.4 \times \mathrm{BH}-12.6 \times \mathrm{CA}-80)}$

for men, and $0.96 \times \sqrt{(\mathrm{UNa} / \mathrm{UCr} / 10) \times(8.6 \times \mathrm{BW}+5.1 \times \mathrm{BH}-4.7 \times \mathrm{CA}-75)}$

for women with indicating body weight $(\mathrm{kg}) ; \mathrm{BH}$, body height $(\mathrm{cm})$; and $\mathrm{CA}$, calendar age (years).

Before the visit to the health check-up, the subjects were asked to answer questionnaires previously prepared by us in- cluding the question, "Do you like salty foods?" Subjects answering the question with "yes" were assigned to the "salt preference" group; if the answer was "no", the subject was assigned to the non-salt preference group. Those whose daily salt intake calculated from Kawasaki's formula exceeded $10 \mathrm{~g}$ were considered excessive salt consumers.

Values are expressed as means \pm SD. Gender differences and differences between the salt preference and nonpreference groups were analyzed by the chi-squared test; an unpaired t- test was used to compare other variables between these groups. A p value less than 0.05 was accepted as indicating statistical significance.

\section{Results}

Male subjects were $51 \pm 8$ years old and female subjects were $52 \pm 8$ years old; respective body weights were $68.2 \pm 9.4$ and $56.1 \pm 8.8 \mathrm{~kg}$; and body mass indices, $23.9 \pm 2.8$ and $23.2 \pm 3.4 \mathrm{~kg} / \mathrm{m}^{2}$. Systolic/diastolic blood pressure was $121 \pm$ $18 / 76 \pm 11 \mathrm{~mm} \mathrm{Hg}$ in men and $118 \pm 19 / 73 \pm 11 \mathrm{~mm} \mathrm{Hg}$ in women. Antihypertensive drugs were taken by $15 \%$ of men and $9 \%$ of women. Daily salt intake was $13.5 \pm 3.5 \mathrm{~g}$ in men and $12.4 \pm 3.1 \mathrm{~g}$ in women. When the salt intake was adjusted for body weight, adjusted salt intake was $0.20 \pm 0.06$ $\mathrm{g} / \mathrm{day} / \mathrm{kg}$ in men and $0.23 \pm 0.06 \mathrm{~g} / \mathrm{day} / \mathrm{kg}$ in women. Except for age, these parameters represented significant differences between men and women.

Salt preference subjects accounted for $42 \%$ of men and $24 \%$ of females, a significant gender difference. In men the age differed significantly between the salt preference group and the non-salt preference group, while women showed significant differences in body weight, body mass index, and proportion taking antihypertensive drugs between salt preference and non-salt preference groups (Table 1). Male subjects had significantly higher salt intake in the salt preference group $(14.1 \pm 3.9 \mathrm{~g})$ than in the non-salt preference group $(13.2 \pm 3.2 \mathrm{~g})$, which also was true for female subjects (13.3 \pm 3.1 vs. $12.2 \pm 3.1$ g; Fig. 1).

However, among men, excessive salt consumers those whose calculated daily salt intake exceeded $10 \mathrm{~g}$, accounted $85 \%$ of the salt preference group and $84 \%$ of the non-salt preference group; among women, excessive consumers comprised $88 \%$ of the salt preference group and $76 \%$ of the non-salt preference group (Fig. 2). Women whose daily salt intake was less than $6 \mathrm{~g}$ numbered five $(2 \%)$ in the non-salt preference group; such a low intake was seen in only one or two subjects (about 2\%) in each of other three groups defined by degree of salt preference and gender (Fig. 2).

\section{Discussion}

The present study indicated that excessive salt consumers (those whose daily salt intake exceeded $10 \mathrm{~g}$ according to the spot urine method) accounted for approximately $80 \%$ of the salt preference groups and also of the non-salt preference groups; accordingly, a simple question concerning for 
Table 1. Baseline Characteristics of Questionaire-Defined Salt Preference and Non-Salt Preference Groups in Male and Female for Health-Checkups Participants

\begin{tabular}{|c|c|c|c|c|}
\hline & $\begin{array}{c}\text { Men } \\
\text { Salt preference } \\
\text { group } \\
\end{array}$ & $\begin{array}{l}\text { Non-salt preference } \\
\text { group }\end{array}$ & $\begin{array}{c}\text { Women } \\
\text { Salt preference } \\
\text { group } \\
\end{array}$ & $\begin{array}{c}\text { Non-salt preference } \\
\text { group } \\
\end{array}$ \\
\hline Number of participants & 189 & 265 & 66 & 205 \\
\hline Age (years old) & $50 \pm 8$ & $52 \pm 8 *$ & $51 \pm 8$ & $52 \pm 8$ \\
\hline Body weight (kg) & $68.4 \pm 9.9$ & $68.2 \pm 8.1$ & $58.4 \pm 10.3$ & $55.3 \pm 8.2 * *$ \\
\hline Body mass index $\left(\mathrm{kg} / \mathrm{m}^{2}\right)$ & $24.2 \pm 2.8$ & $23.9 \pm 2.5$ & $24.1 \pm 3.7$ & $22.9 \pm 3.2 * *$ \\
\hline Systolic blood pressure (mm Hg) & $121 \pm 17$ & $122 \pm 18$ & $119 \pm 15$ & $117 \pm 20$ \\
\hline Diastolic blood pressure $(\mathrm{mm} \mathrm{Hg})$ & $75 \pm 11$ & $76 \pm 11$ & $74 \pm 11$ & $73 \pm 11$ \\
\hline Antihypertesive drugs (\%) & 16 & 12 & 15 & $6^{* *}$ \\
\hline
\end{tabular}

\section{(g/day)}

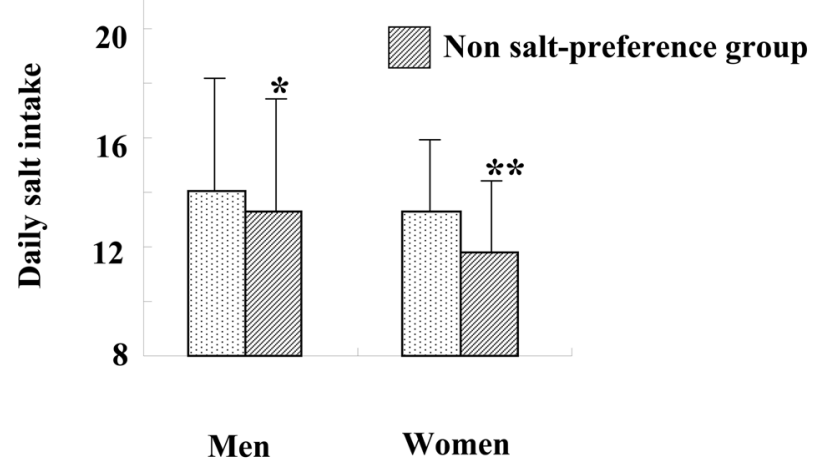

Figure 1. Daily salt intake determined by the spot urine method in salt preference and non-salt preference groups. $* \mathbf{p}<0.05$ vs. male salt preference group, $* * \mathbf{p}<0.05$ vs. female salt preference group. Data was obtained from residents in the Iwate area who underwent a check-up from April 2001 to March 2002 in males, and from April 2001 to March 1003 in females.

salt preference cannot identify excessive salt consumer. Ohta et al (17) also reported that a subjective questionnaire response does not reflect actual individual salt intake; they found salt intake estimated from 24-hour urine collections to be similar between a salt conscious group and a non-salt conscious group defined by the questionnaire. These results strongly support objective measurement of salt intake by methods such as spot urine calculations and 24-hour urine collections.

We used the spot urine method of Kawasaki et al to measure daily salt intake based on convenience for participants. At our health check-up center, participants routinely are advised to arrive at our center before breakfast, and undergo urinalysis and blood sampling at arrival. This urine sample can be used as the spot urine test for estimation of salt intake without any change of procedures. We recommend evaluation of salt intake by the spot urine method at all health check-up centers.

The daily salt intake of $13.5 \pm 3.5 \mathrm{~g}$ in men and $12.4 \pm 3.1 \mathrm{~g}$ in women obtained by spot urine calculations was similar to our previous data (13 to $14 \mathrm{~g}$ in men, 11 to $12 \mathrm{~g}$ in women) obtained by measuring 24-hour urinary sodium excretion in residents of Iwate with essential hypertension (18) and also in health check-up patients (19). This comparison suggests that the spot urine method is about as reliable as a 24 hour urine collection.

Although we found a simple questionnaire method to be inadequate to determine excessive salt intake, statistically significant differences in the daily salt intake and also in the excessive salt consumers in women still could be found between the salt preference group and the non-salt preference group. These results suggest that the questionnaire can be useful for some epidemiological purposes. Interestingly, a much lower percentage of women indicated salt preference than men, although women showed higher salt intake when salt intake was adjusted by body weight. This discrepancy requires further physiologic and possibly psychological investigation.

Keeping intake of sodium chloride below $10 \mathrm{~g}$ per day, as proposed in 1979 in Japan, falls short of ideal but represents a first step in reduction. Salt intake of early man was estimated to be approximately $1 \mathrm{~g}$ by analyses of paleolithic nutrition (20), and many million years of human history have involved a state of chronic salt depletion; this suggests that modern humans still retain the genes needed to adapt to a low-salt diet. In 2004, Japanese Society of Hypertension recommended a daily intake of less than $6 \mathrm{~g}$ of salt not only for hypertensive patients but also for healthy persons (16), as paralleling recommendations in many other countries $(21$, 22).

Some limitations of our study are apparent. First, al- 


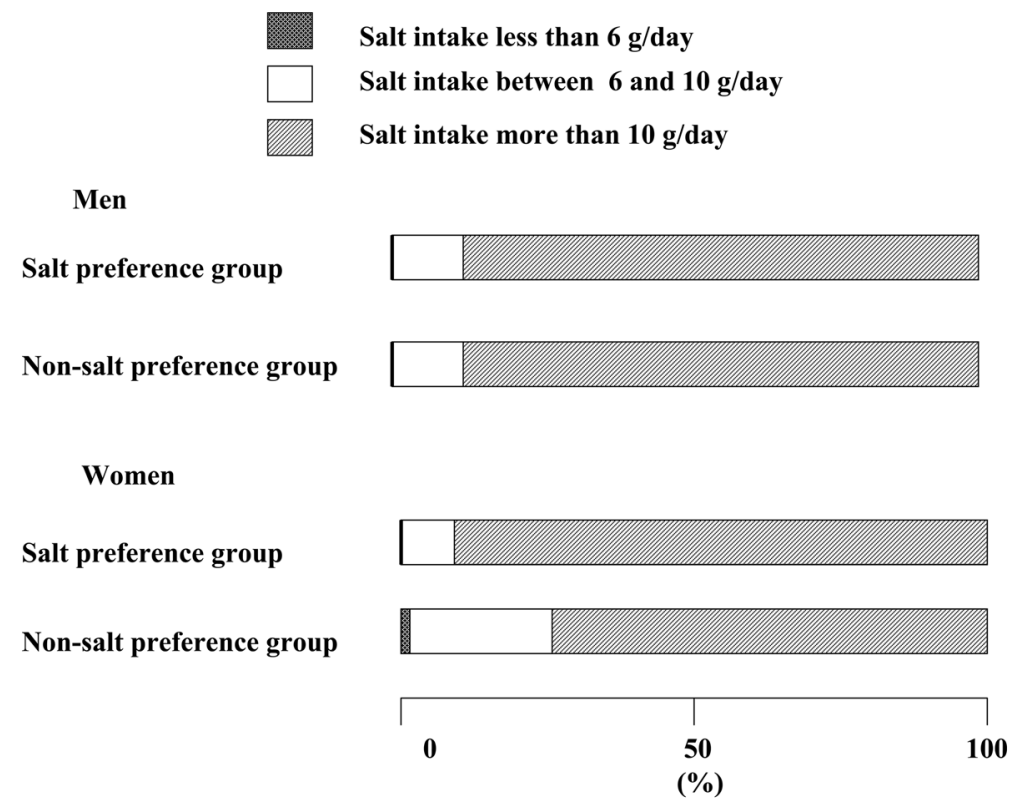

Figure 2. Salt intake representing less than $6 \mathrm{~g} / \mathrm{day}, 6$ to $10 \mathrm{~g} / \mathrm{day}$, and more than $10 \mathrm{~g} / \mathrm{day}$ in the salt preference group and the non-salt preference group. Data was obtained from residents in the Iwate area who underwent a check-up from April 2001 to March 2002 in males, and from April 2001 to March 1003 in females.

though the spot urine method was confirmed to be appropriate for use epidemiologic studies $(12,13)$, reliability for estimation of individual salt intake has not been fully determined. The $95 \%$ confidence interval of salt intake by the spot urine method was 5 to $10 \mathrm{~g}$ for subjects consuming 6 to $8 \mathrm{~g}$ salt diet for 1 week, suggesting over- or underestimation by approximately 2 to $3 \mathrm{~g}$ of sodium chloride (14). One should keep in mind that this also is the case with 24 hour urine collections, considered the most reliable method (23). Previous studies $(24,25)$ have reported wide fluctuations in 24-hour urinary sodium excretion in subjects whose salt intake is kept constant. Reliability should be estimated in salt intake states other than $7 \mathrm{~g}$ per day. Second, a single measurement of daily salt intake is known to be unreliable. Ambulatory individual daily salt intake varies considerably over time; Kawasaki et al (26) reported that individual subjects' standard deviation for salt intake was $25 \%$ to $27 \%$ in estimates based on 24 hour urine collections over 3 consecutive weeks. Accordingly, repeated measurements of daily salt intake are necessary to accurately evaluate daily salt consumption. The spot urine method presents a noninvasive and easy method for obtaining measurements on multiple occasions. Further studies are needed to determine the optimal number of measurements.

In summary, a questionnaire item concerning salt preference, although convenient, was not an effective indicator of excessive salt consumption. Convenient but reliable methods to estimate salt intake, like the spot urine method, are recommended when salt intakes are to be measured in a great many persons.

\section{References}

1. Meneton $P$, Jeunemaitre $X$, de Wardener HE, MacGregor GA Links between dietary salt intake, renal salt handling, blood pressure, and cardiovascular diseases. Physiol Rev 85: 679-715, 2005.

2. de Wardener HE, MacGregor GA. Harmful effects of dietary salt in addition to hypertension. J Hum Hypertens 16: 213-223, 2002.

3. Tsugane S, Sasazuki S, Kobayashi M, Sasaki S. Salt and food intake and subsequent risk of gastric cancer among middle-aged Japanese men and women. Br J Cancer 90: 128-134, 2004.

4. Shikata K, Kiyohara Y, Kubo M, et al. A prospective study of dietary salt intake and gastric cancer incidence in a defined Japanese population: The Hisayama study. Int J Cancer 119: 196-201, 2006.

5. Intersalt Cooperative Research Group. Intersalt: an international study of electrolyte excretion and blood pressure. Results for 24 hour urinary sodium and potassium excretion. BMJ 297: 319-328, 1988.

6. Zhou BF, Stamler J, Dennis B, et al. Nutrient intakes of middle- aged men and women in China, Japan, United Kingdom, and United States in the late 1990s: the INTERMAP study. J Hum Hypertens 17: 623-630, 2003.

7. Department of Health Care, Ministry of Health and Welfare of Japan. Results of a nutrition survey in 2004. The condition of health care in Japan. Daiichi Shuppan, Tokyo, 2006: 47 (in Japanese).

8. Pietinen P. Estimating sodium intake from food consumption data. Ann Nutr Metab 26: 90-99, 1982.

9. Scachter J, Harper PH, Radin ME, et al. Comparison of sodium and potassium intake with excretion. Hypertension 2: 685-699, 1980.

10. Etoh T. Results of a self-administered questionnaire for salt restriction program among participant doctors of educational meeting for hypertension. Bull Jpn Soc Hypertens 30: 8-10, 2006 (in Japanese).

11. Kawasaki T, Itoh $K$, Uezono $K$, Sasaki H. A simple method for 
estimating $24 \mathrm{~h}$ urinary sodium and potassium excretion from second morning voiding urine specimen in adults. Clin Exp Pharmacol Physiol 20: 7-14, 1993 (erratum in: Clin Exp Pharmacol Physiol 20:199, 1993).

12. Kawasaki T, Itoh $\mathrm{K}$, Uezono $\mathrm{K}$, et al. Investigation of high salt intake in a Nepalese population with low blood pressure. J Hum Hypertens 7: 131-140, 1993.

13. Iseki $\mathrm{K}$, Iseki $\mathrm{C}$, Itoh $\mathrm{K}$, et al. Urinary excretion of sodium and potassium in a screened cohort in Okinawa, Japan. Hypertens Res 25: 731-736, 2002.

14. Kawamura M, Kusano Y, Takahashi T, Owada M, Sugawara T. Effectiveness of a spot urine method in evaluating daily salt intake in hypertensive patients taking oral antihypertensive drugs. Hypertens Res 29: 397-402, 2006.

15. Holbrook JT, Patterson KY, Bodner JE, et al. Sodium and potassium intake and balance in adults consuming self-selected diets. Am J Clin Nutr 40: 786-793, 1984.

16. Guidelines Subcommittee. Japanese Society of Hypertension Guidelines for the Management of Hypertension (JSH 2004). Hypertens Res 29: S1-S6, 2006.

17. Ohta $Y$, Tsuchihashi $T$, Ueno $M$, et al. Relationship between the awareness of salt restriction and the actual salt intake in hypertensive patients. Hypertens Res 27: 243-246, 2004.

18. Nakajima J, Kawamura M, Fujiwara T, Hiramori K. Body height is a determinant of seasonal blood pressure variation in patients with essential hypertension. Hypertens Res 23: 587-592, 2000.
19. Kawamura M, Kimura Y, Takahashi K, et al. Relation of urinary sodium excretion to blood pressure, glucose metabolism, and lipid metabolism in residents of an area of Japan with high sodium intake. Hypertens Res 20: 287-293, 1997.

20. Eaton SB, Konner M. Paleolithic nutrition. N Engl J Med 312: 283-289, 1985.

21. Chobanian AV, Bakris GL, Black HR, et al. The Seventh Report of the Joint National Committee on Prevention, Detection, Evaluation, and Treatment of High Blood Pressure. JAMA 289: 25602572, 2003.

22. Williams B, Poulter NR, Brown MJ, et al. Guidelines for management of hypertension: report of the fourth working party of the British Hypertension Society,-2004-BHS IV. J Hum Hypertens 18: 139-185, 2004.

23. Leiba A, Vald A, Peleg E, Shamiss A, Grossman E. Does dietary recall adequately assess sodium, potassium, and calcium intake in hypertensive patients? Nutrition 21: 462-466, 2005.

24. Black DAK, Thompson AE. Day-to-day changes in sodium and water output with and without posterior pituitary extract. Clin Sci 10: 511-520, 1951.

25. Baldwin D, Alexander RW, Warner EG. Chronic sodium chloride challenge studies in man. J Lab Clin Med 55: 362-375, 1960.

26. Kawasaki T, Ueno M, Uezono K, et al. Average urinary excretion of sodium in 24 hours can be estimated from a spot-urine specimen. Circ J 46: 948-953, 1982.

(C) 2008 The Japanese Society of Internal Medicine

http://www.naika.or.jp/imindex.html 